\title{
Improving Care for Behavioral Health Conditions under the Affordable Care Act: The View from a Health and Aging Policy Fellow
}

\author{
Kara Zivin, Associate Professor, Department of Psychiatry, University of Michigan
}

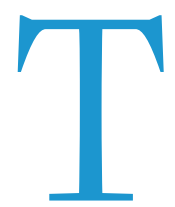

rained as a behavioral health services researcher, I came to the APSA's Congressional Fellowship Program (CFP) seeking to learn about how the Patient Protection and Affordable Care Act (ACA) of 2010 had been and would be influencing individuals with behavioral health conditions (i.e., mental health and substance use disorders). As the ACA will undoubtedly be the landmark healthcare legislation of my lifetime, I was eager to understand its implications for the delivery, quality, costs of, and access to healthcare, particularly for this traditionally disenfranchised population.

Many fellows sought placements to expose them to a wide range of topics, such as working in the personal office of a specific Representative or Senator. However I believed, and later confirmed, that a more targeted approach through obtaining an executive branch position would afford me a greater likelihood of being able to focus on my substantive interests. When I applied to the CFP, I focused my statement of interest on recommendations derived from a 2012 Institute of Medicine (IOM) report, "The Mental Health and Substance Use Workforce for Older Adults: In Whose Hands?" (Institute of Medicine 2012). This report was generally focused on the pending geriatric behavioral health services provider shortage, but it also examined potential opportunities to try to improve the quality of behavioral health care for older adults. I had noted two recommendations in particular that were of interest related to the Centers for Medicare and Medicaid Services (CMS):

- "CMS should evaluate alternative methods for funding primary care and other personnel who provide evidence-based models of care to older adults with mental health and substance use conditions. This should include reimbursing care managers as well as the psychiatrists and other mental health specialists providing supervision of their work."

- "CMS should evaluate alternative payment methods to encourage effective deployment of the workforce to provide integrated primary care, chronic disease self-management, and health promotion for older adults receiving care in Community Mental Health Centers and other specialty mental health settings."

Therefore, when I arrived in Washington, DC, in the fall of 2013, I knew that I would likely be most interested in obtaining a placement at CMS, as I saw CMS as the epicenter of health care, given its enormous budget and hence, ability to influence how other payers,

Kara Zivin is an associate professor in the department of psychiatry at the University of Michigan Medical School. She is also a research health scientist at the VA Center for Clinical Management Research in Ann Arbor, Michigan. After Kara ended her position as Senior Advisor to the Centers for Medicare and Medicaid Services, she became a senior researcher at Mathematica Policy Research. Kara's research examines the impact of health policies on clinical, functional, and financial outcomes among individuals with mental disorders. She can be reached at kzivin@umich.edu. including commercial providers, delivered health care. I also saw it as playing a potentially important role in improving the quality of care for behavioral health conditions through alternative payment models. I was aware that the CMS Center for Medicare and Medicaid Innovation (CMMI) was playing a role in the implementation of some components of the ACA, but was not familiar with particular centers or programs within CMMI.

I soon learned that CMMI was established by section $1115 \mathrm{~A}$ of the Social Security Act (as added by section 3021 of the ACA). Congress created CMMI to test "innovative payment and service delivery models to reduce program expenditures ... while preserving or enhancing the quality of care" for those individuals who receive Medicare, Medicaid, or Children's Health Insurance Program (CHIP) benefits (Centers for Medicare and Medicaid Innovation 2016). Congress provided the Secretary of Health and Human Services (HHS) with the authority to expand the scope and duration of a model being tested through rulemaking, including the option of testing on a nationwide basis. In order for the Secretary to exercise this authority, a model must either reduce spending without reducing the quality of care, or improve the quality of care without increasing spending, and must not deny or limit the coverage or provision of any benefits. These determinations are made based on evaluations performed by CMS and the certification of CMS's Chief Actuary with respect to spending.

Although I had the good fortune of interviewing widely for fellowship positions, including in several legislative branch offices and executive branch positions, during one of my last interviews, I learned about a position that appeared almost too good to be true-it was an opening within the Seamless Care Models Group of CMMI to work on the Comprehensive Primary Care Initiative (CPC). CPC was one of many initiatives authorized under Section 3021 of the ACA. At the time, CPC was beginning its second of this four-year multi-payer initiative designed to strengthen primary care.

$\mathrm{CPC}$ involves the collaboration of CMS with commercial and state health insurance plans in seven US regions to offer populationbased care management fees and shared savings opportunities to participating primary care practices to support the provision of a core set of five "Comprehensive" primary care functions (Baron and Davis 2014). These five functions are 1) risk-stratified care management; 2) access and continuity;3) planned care for chronic conditions and preventive care; 4) patient and caregiver engagement; and 5) coordination of care across the medical neighborhood (Center for Medicare and Medicaid Services 2016).

During year two of CPC, participating practices were going to be given a choice of three advanced primary care strategies, including behavioral health integration (BHI), comprehensive medication management, and self-management support. The team was looking 
for a subject matter expert with behavioral health expertise, and I was a good match for the position.

In my previous work for the Department of Veterans Affairs (VA), and as a faculty member at the University of Michigan department of psychiatry, I had participated in both research studies and evaluations of $\mathrm{BHI}$ implementation, including both care management (CM) and collocated collaborative care (CCC). To summarize, CM includes monitoring of adherence, outcomes, and side effects; involves decision support, patient education, and activation; and provides assistance in referral to specialty mental health care programs when needed. CCC involves one or more mental health professionals who are integral components of the primary care team and physically located in the primary care setting, and provides assessment and psychosocial treatment as needed for a variety of mental health problems. Both CM and CCC approaches are designed to improve quality of care by facilitating better care coordination for patients and providers.

The CPC was a large initiative including nearly 500 practice sites with over 2,00o participating providers serving approximately $2,700,000$ patients, as well as nearly 40 public and private payers that was providing a financial incentive for practices to engage practice redesign that could include BHI. Findings from CPC would have important implications for the potential expansion of funds for primary care transformation, which could include widespread BHI. evaluations of the implementation and impact of their initiatives. Since the launch of CMMI, there have been dozens of initiatives, of which CPC is only one, and multiple contractors routinely bid on the work that will assist CMMI, and CMS more broadly, with its demonstration projects.

A particularly memorable experience happened when I was in a meeting with the CPC team and one of its external contractors. The contractor team handed out 20 pages worth of illustrations on $8.5 \mathrm{x} 14$ inch paper (legal size) using at most 6 point font. They also handed out magnifying glasses so that we could read the tiny font on this large paper. The illustrations included what they called "swim lanes," which were long horizontal boxes demonstrating relationships between CMS contractors, CMMI, practices, providers, and beneficiaries. Another graphic created internally by CMS also tried to highlight the relationships between regional and national components of CPC, relevant training materials, support, management, and measurement. I believed I was able to locate where I fit into the complex matrix of the CPC initiative in a small box labeled "subject matter faculty." I felt like a tiny cog embedded in an enormous machine.

I had the good fortune of being able to travel as part of my CFP experience to two of the seven different regions participating in CPC: Ohio and Oregon. I attended their biannual regional meetings for $\mathrm{CPC}$ and heard from participating payers, providers, and

\section{Although I had the good fortune of interviewing widely for fellowship positions, during one of my last interviews, I learned about a position that appeared almost too good to be true...}

The work I was being asked to conduct within CPC was directly aligned with the recommendations set forth in the IOM report I had referenced in my CFP application.

Not only was I quickly included as a core CPC team member within CMMI, but I was also afforded the opportunity to carve out a unique piece of work for the team. With the support of my CPC colleagues, I developed the 2014 CPC Behavioral Health Integration Survey, which we administered to each participating CPC practice that elected to focus on $\mathrm{BHI}$ or that had a behavioral health provider on staff. Of 188 eligible practices, 161 completed surveys $(86 \%$ response rate) that included 6 substantive domains (integrated space, training, access, communication and coordination, treatment planning, and available resources) and 5 disorders (depression, anxiety, pain, alcohol use disorder, and cognitive disorders). We reported our findings to the participating practices, and are in the process of publishing them in the peer-reviewed scientific literature. The experience of both developing a deliverable and seeing it through to completion within CMS, as well as having the opportunity to participate in overall day-to-day work for CPC was an eye opening and ultimately, career changing experience.

As with many CMMI demonstrations, CPC is a highly complex, multifaceted initiative that involves numerous patients, providers, payers, and components. The team had developed several colorful graphic displays to try to illustrate the various elements of CPC. A key difference from my prior work was that unlike my experiences within the VA, in which our funding for research and evaluation of VA initiatives was largely derived from the VA itself, CMS hires a multitude of external contractors for a variety of roles. Contractors provide technical assistance for participating practices, including educational materials as well as electronic platforms to conduct reporting of health and financial indicators. CMS contractors conduct the patients about their experiences overall with CPC, and in their work focused on BHI. I was also able to attend the annual national CPC meeting at the CMS headquarters in 2014 and 2015, where I heard presentations by CMS staff, CPC staff, the external evaluation contractor, which was Mathematica Policy Research (MPR), as well as other federal officials from a range of agencies in addition to payers and providers participating in CPC. It was gratifying to hear about the positive experiences that CPC practices were having, as the care management fees provided by CPC were allowing practices to make strategic changes to engage in primary care redesign. It was also useful to hear about the challenges that practices were facing in a variety of domains, and how the CPC staff and their contractors sought to assist them.

Of particular salience to my career, I carefully observed the relationship between the CPC core team and MPR. I had spent my career to date conducting primarily grant funded research, with some evaluation experience, and was curious about how a federal agency like CMS interacted with large contractors. I was pleasantly surprised at how collaborative the relationship appeared, which led me to pursue an opportunity to work for MPR after I completed my work at CMS. CMS is keenly interested and invested in external evaluation findings because they can have implications for whether a model will be expanded and continued once the demonstration has ended. Stated another way, these findings will directly inform possible changes in health care payment and policy.

It was also an interesting juxtaposition to see the vast sums of money being invested in contract research as compared to ever dwindling funds supplied by the National Institutes of Health (NIH) for investigator initiated research endeavors. Unlike my experience with grant funded research that did not always appear to have a direct impact on policy, it became abundantly clear to me that contract 
work can have direct and important policy implications. Findings from the evaluation of CMMI initiatives could both influence and be influenced by the upcoming election in 2016 .

I will always value the experience I had working for CMS. I came to appreciate the fast moving pace, and the significant personal and professional dedication of the CMS staff to the triple aim of improving of healthcare quality and access while decreasing costs (Berwick, Nolan, and Whittington 2008). I remain hopeful that the CPC and other models being tested in CMMI can achieve their intended results. I became much more informed about how healthcare redesign efforts made possible as a result of the ACA could have benefits for many patients, including those with behavioral health conditions, and look forward to remaining engaged in this process as it unfolds over time.

\section{R E F E R E N C E S}

Baron, Richard J., and Karen Davis. 2016. "Accelerating the adoption of high-value primary care: A new provider type under Medicare?" The New England Journal of Medicine. 370 (2): 99-101.

Berwick, Donald M., Thomas W. Nolan, and John Whittington. 2008. "The Triple Aim: Care, Health, And Cost." Health Affairs 27 (3): 759-769.

Centers for Medicare and Medicaid Innovation. 2016. "About the CMS Innovation Center." https://innovation.cms.gov/about/index.html. Accessed 04/09/2016.

Centers for Medicare and Medicaid Services. 2016. "Comprehensive Primary Care Initiative." https://innovation.cms.gov/initiatives/comprehensive-primarycare-initiative/. Accessed 04/09/2016.

Institute of Medicine. 2012. The Mental Health and Substance Use Workforce for Older Adults: In Whose Hands? Washington, DC: The National Academies Press.

\section{Office Assignments: 2015-2016 APSA Congressional Fellowship Program}

$\mathrm{F}$ ounded in 1953, the APSA Congressional Fellowship Program is the nation's oldest and most prestigious congressional fellowship. More than sixty years later, the program remains devoted to its original objective of expanding knowledge and awareness of Congress. For nine months, select political scientists, journalists, federal employees, health policy specialists, and other domestic and international professionals gain "hands on" understanding of the legislative process by serving on congressional staffs. Through this unique opportunity, the association enhances public understanding of policy-making and improves the quality of scholarship, teaching, and reporting on American national politics. For more information about the program visit https://www.apsanet.org/cfp. The assignments for 2015-2016 are listed below.

\section{HOUSE}

La Rissa Ferrell

Rep. Alcee Hastings (D-FL)

\section{Lisa Hager}

Rep. Daniel Lipinski (D-IL)

Thomas Ringenberg

Rep. William Lacy Clay (D-MO)

\section{Yushi Alex Saito}

Rep. Chuck Fleischmann (R-TN)

Clayton Swope

Rep. Derek Kilmer (D-WA)

\section{SENATE}

Brian Alexander

Sen. Jack Reed (D-RI)

Justin Brown

Sen. Brian Schatz (D-HI)

Christopher Burdick

Sen. Sherrod Brown (D-OH)

Stephen Dietz

Sen. Robert Casey (D-PA)
Shannon Dorsey

Sen. Amy Klobuchar (D-MN)

Gene Gerzhoy

Sen. Edward Markey (D-MA)

Maria M. Givens

Sen. Jeff Merkley (D-OR)

Nicholas Howard

Sen. Orrin Hatch (R-UT)

David Keahey

Sen. Chris Murphy (D-CT)

Teri Kennedy

Sen. Jeff Flake (R-AZ)

Ryan Matheny

Sen. Ron Wyden (D-OR)

Dayna Matthew

Sen. Debbie Stabenow (D-MI)

Mark Owens

Sen. Orrin Hatch (R-UT)

Nathan Paxton

Sen. Angus King (I-ME)
Jeanette Roberts

Sen. Edward Markey (D-MA)

Joel Walsh

Sen. Claire McCaskill (D-MO)

\section{COMMITTEES}

Randy Cartwright

House Committee on Foreign Affairs (Majority)

\section{Sarah Khasawinah}

Senate Special Committee on Aging (Majority)

\section{Travis Johnston}

Senate Committee on Health, Education, Labor and Pensions (Minority)

\section{Robert Mabry}

House Committee on Energy and Commerce (Majority)

\section{Thomas Mayes}

House Committee on Ways and Means, Subcommittee on Health (Majority) 


\section{Brian McCuen}

House Committee on Foreign Affairs (Majority)

\section{OTHER LEGISLATIVE BRANCH PLACEMENTS}

\section{Jamie Kuhne}

Congressional Research Service

\section{EXECUTIVE BRANCH AND OTHER PLACEMENTS}

Julie Bobitt

Office of the Surgeon General

\section{Julie Carter}

Administration for Community Living, Department of Health and Human Services

\section{Megan Christensen}

Office of the Surgeon General

\section{Jamie Davis}

Elder Justice Initiative, Department of Justice

\section{Robert Ferguson}

Center for Clinical Standards \& Quality, Centers for Medicare \& Medicaid Services

\section{Stephanie Firestone}

Office of Community Planning and Development, Department of Housing and Urban Development

\section{Tamara Harris}

Centers for Medicare and Medicaid Services and National Institute on Aging

\section{Jacqueline Kung}

Department of Health and Human Services

\section{Hillary Lum}

Colorado Department of Healthcare Policy and Finance

\section{Rebecca Mabe}

The RAND Corporation, the Eldercare Workforce Alliance, and the Substance Abuse and Mental Health Services Administration

\section{Gina McCaskill}

Community Catalyst

\section{Aditi Sen}

Office of Health Policy, Office of the Assistant Secretary for Planning and
Evaluation, Department of Health and Human Services

\section{Hiral Shah}

Health Resources and Services Administration

\section{Latrice Vinson}

Office of Geriatrics and Extended Care, Central Office, Department of Veterans Affairs

\section{Y. Claire Wang}

Office of the Assistant Secretary for Health, Department of Health and Human Services

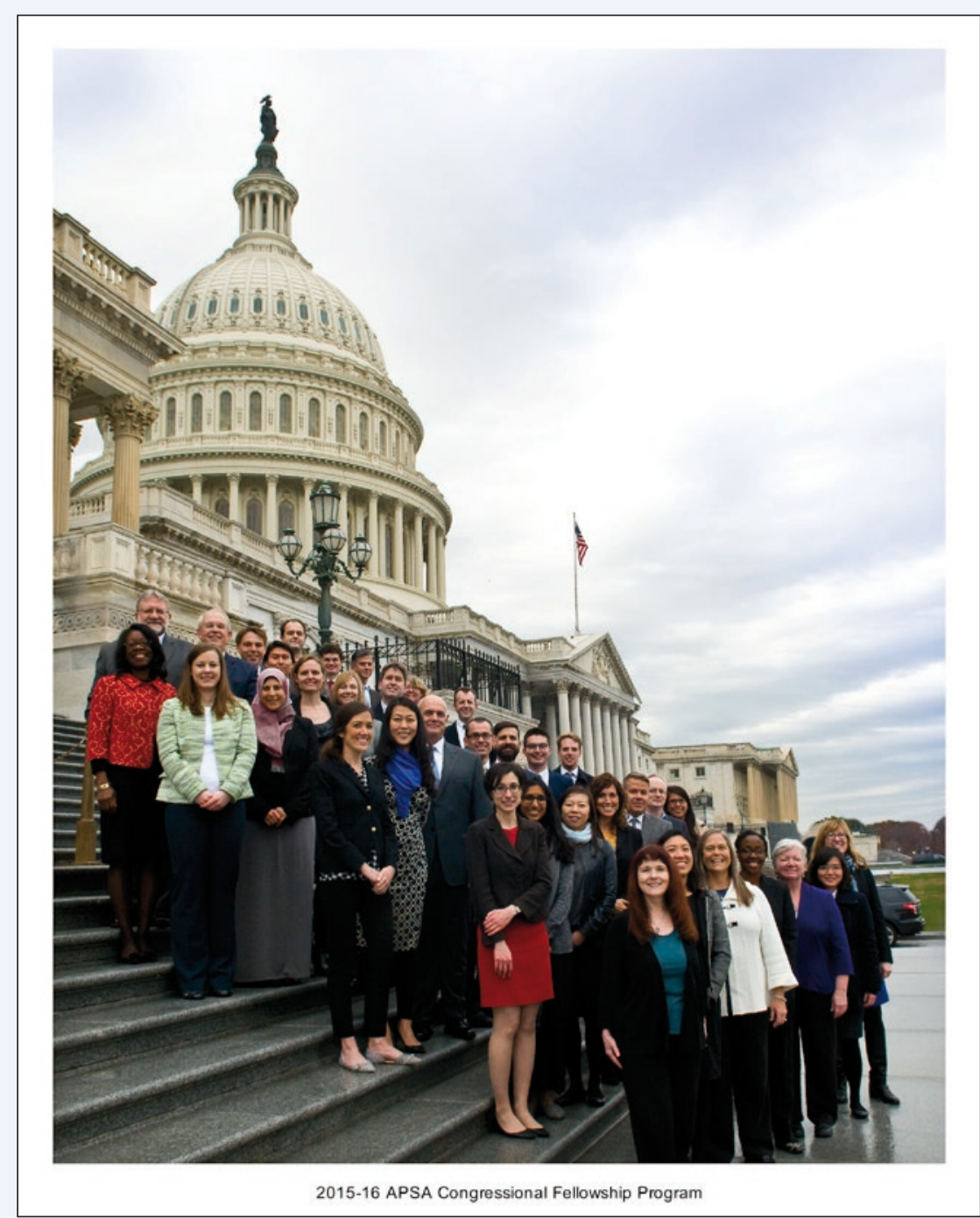

Top row, L to R: Dayna Matthew, David Keahey, Thomas Mayes, Mark Owens, Yushi Alex Saito, Nicholas Howard, Robert Ferguson, Randy Cartwright

Fourth row, L to R: Lisa Hager, Sarah Khasawinah, Jamie Kuhne, Julie Bobitt, Christopher Burdick, Shannon Dorsey, Brian Alexander

Third row, L to R: Megan Christensen, Jacquelyn Kung, Robert Mabry, Clayton Swope, Nathan Paxton, Elliot Mamet, Stephen Dietz

Second row, L to R: Kara Abramson, Hiral Shah, Y. Claire Wang, Stephanie Firestone, Ryan Matheny, Brian McCuen, Maria M. Givens

Bottom row, L to R: Teri Kennedy, Hillary Lum, Jamie Davis, Latrice Vinson, Jeanette Roberts, Nattamon Punbhochar, Rebecca Mabe

Not pictured: Gene Gerzhoy, Travis Johnston, Thomas Ringenberg, Joel Walsh, Justin Brown, Tamara Harris, Gina McCaskill, Julie Carter, Aditi Sen, La Rissa Ferrell 